\title{
LA DEBILIDAD Y EL MIEDO: FACTORES CONDICIONANTES DE LA ACTITUD DE LA IGLESIA ANTE LA REVOLUCIÓN. GUATEMALA (1945 - 1954)
}

\author{
POR \\ Francisco Javier Gómez Díez \\ Universidad Complusense de Madrid
}

\begin{abstract}
Resumen
Este trabajo intenta comprender el comportamiento de la Igiesia católica en Guatemala durante la Década Revolucionaría considerando dos elementos que lo condicionaron claremente: la debilidad de la lglesia (falta de medios economicos, escasez de sacerdotes, desamparo jurídico, etc.) provocada por el triunfo liberal y agravada por la intransigencia ideológica de los sectores revolucionarios y el miedo que entre los sectores eclesiásticos difundió la movilización que provoca, entre otras cosas, un incremento de las tensiones entre los sacerdotes y sus feligreses.
\end{abstract}

\begin{abstract}
Weakness and fear: conditions in Guatemala revolution attitudes (1945-1954)

This paper analyces two questions with the purpose to understand the behaviour of the Catholic Church in Guatemala during the Décado Revolucionaria. First, the weakness of the Church (a institution without economical resources; without priest; etc.) promoted by the liberal revolution and ideological doctrinarianism of the 1945 movement; and second, the fear of the catholic group originated in the political mobilization fomented by the govenument of the Revolution.
\end{abstract}

La comprensión de la actitud de la Iglesia católica durante la Década Revolucionaria en Guatemala, pasa por el establecimiento de dos elementos con- 
dicionantes de gran importancia: la debilidad de la Iglesia provocada por el triunfo liberal, agravada por las actitudes intransigentes de los que se sentían herederos del liberalismo, y el miedo que entre los sectores eclesiástico difundió la agitación política que desde 1945 se extendió por todo el país.

\section{LA HERENCIA LIBERAL}

Triunfante en Guatemala en 1871, el liberalismo no habría de reconocer a la Iglesia como una sociedad soberana e independiente, y comenzó a desmantelar el poder eclesiástico cuando Justo Rufino Barrios, por entonces Comandante de Occidente, forzó la expulsión de los jesuitas y del Arzobispo Monseñor Piñol y Aycinena. Pronto se suprimieron los diezmos, se prohibió a perpetuidad el retomo de los jesuitas y se nacionalizaron sus bienes; se prohibió el traje talar, fueron extinguidas todas las comunidades religiosas masculinas, confiscándoles también sus bienes, y se expulsó a multitud de sacerdotes, nacionales y extranjeros.

La intención era destruir todos los elementos del poder temporal de la Iglesia, para permitir la máxima centralización en manos del Estado. De este modo, en 1874 la mayor parte de las medidas anticlericales estaban ya en marcha y, en 1879, fueron refrendadas por la nueva Constitución: prohibición de los actos religiosos fuera de los templos, abolición de la enseñanza religiosa en las escuelas nacionales, derogación de los privilegios eclesiásticos, prohibición de heredar a los ministros de culto, matrimonio civil, secularización de los registros civiles y los cementerios, reforma de todos los planes de estudio y supresión de la Pontificia Universidad de San Carlos.

Las múltiples reformas de la Constitución de 1879 , vigente hasta 1944, no modificaron la situación de la Iglesia. Durante todos estos años, sus relaciones con el Estado no variaron substancialmente: fueron expulsados todos los arzobispos, a excepción de Monseñor Durou, y el número de sacerdotes disminuyó considerablemente, fruto del desprestigio de la Iglesia y de la prohibición de que los sacerdotes extranjeros ingresaran en Guatemala. Cuando en 1924 fue expulsado Monseñor Luis Muñoz y Capurón, la Iglesia guatemaiteca había alcanzado el punto más bajo de su historia, con sólo ochenta y cinco sacerdotes, ciento dieciséis partoquias, muchas de ellas de dimensiones grandisimas, y sin seminariol.

1 MILler, Hubert J. La lglesia y el Estado en tiempos de Justo Rufino Barrios, (1871-1885), USAC, Guatemala, 1976; HOLLERAN, Mary P. Church and State in Guatemala, Columbia University Press, New York, 1949; Historia General de la Iglesia en América Latina. Vol. 6. America Central, CEHILA, Salamanca, 1985.

La Iglesia en la Encrucijada

Hispania Sacra 49 (1997) 
Paralelamente la Iglesia experimentó un proceso de descomposición interna. Falta de sacerdotes, se vio obligada a concentrarse en las grandes ciudades, abandonando casi por completo las pequeñas comunidades, en las que se desarrollaron fuertes e independientes las cofradías. Su falta de medios económicos sólo le permitió ser poco más que la servidora espiritual de las clases altas. La carrera religiosa perdió todo su prestigio y la clase alta, educada y con posibilidades económicas, huía de ella. Cuando no se podía evitar que un hijo renunciara a st vocación religiosa, se le enviaba al extranjero, a formarse en el seminario de alguna orden; y, de este modo, la Iglesia guatemalteca no podía contar con él $1^{2}$. Mientras, sólo las clases populares nutrían, y muy escasamente, las filas del sacerdocio, surgiendo un clero pésimamente preparado y carente de medios para llevar adelante su misión.

Desde el punto de vista de la Iglesia, la superación de los problemas pasaba por interrumpir la lista de Arzobispos expulsados y, de este modo, estabilizar el gobierno eclesiástico. Para ello, la Santa Sede nombró a Monseñor Jorge Caruana, un maltés con grandes contactos en Estados Unidos - había sido capellán de su ejército--, Administrador Apostólico del Arzobispado de Guatemala, con la intención de que lo visitara y propusiera una solución.

Caruana tuvo que tomar en consideración la conveniencia de dividir el Arzobispado, para dificultar la inexistencia de autoridad episcopal en el caso de una nueva expulsión; el nacionalismo guatemalteco, que deseaba el nombramiento de un prelado nacional; la influencia del mundo francés entre los liberales y la presencia en Guatemala de una única orden masculina, la Congregación de la Misión de San Vicente Paúl, confesores de las Hermanas de la Caridad. De este modo, el 4 de agosto de 1928, a propuesta de Caruana, la Santa Sede nombró a Luis Durou y Suré, paúl, francés, miembro de la Legión de Honor y Capellán del Hospital General, Arzobispo de Guatemala y a Monsenor Jorge García y Caballero, guatemalteco, primer obispo de Los Altos.

Desde el primer momento se dispuso Monseñor Durou a visitar todas las Parroquias de la Arquidiócesis ${ }^{3}$, y escribió a sus párrocos, solicitándoles un

2 Es muy significativo que a finales de los cuarenta, una distinguida familia guatemalteca se opusiera a que uno de sus hijos ingresara en el noviciado jesuita de El Salvador, y no en EE.UU., "como si fuera a hacerse fraile de broma metiendose en un pueblo de El Salvador". Archivo de la provincia jesuita de centroamérica (San Salvador) [en adelante, ASJ-CA] 8.4 Guatemala: Bariain Viceprovincial: carta de Echarri a Bariain 10.III.1949.

3 Según Agustín ESTRADA MONROY, Datos para la Historia de la Iglesia en Guatemala, Sociedad de Geografia e Historia, Guatemala, 1979, vol. 3, Monsen̂or Durou visitó: Livingston, Zacapa, Salamá, Rabinal, El Petén, Jutiapa, Asunción Mita, El Progseso, el Vicariato Apostólico de Verapaz, Antigua y sus vecindades, Jalapa, San Felipe Retalhuleu, San Antonio Suchitepéquez, Chimaitenango, San Martín Jilotepeque, Mazatenango, Santa Lucia Cotzumalguapa, Escuintla y el Puerto de San José. Lamentablemente el Archivo Histórico Arquidiocesano (Guatemala) [en adelante, AHA] sólo 
informe sobre la administración y los bienes parroquiales; el número de las iglesias, capillas y oratorio, con las licencias en orden; el grado de cumplimiento de diversos preceptos (el bautismo, la pascua, la asistencia a misa, etc.); la instrucción religiosa de los fieles y la catequesis que se impartía; la existencia de sociedades piadosas, y el carácter de sus estatutos; la forma de celebrar las principales festividades; la gravedad de la superchería y los vicios; el problema matrimonial y el desarrollo del protestantismo4.

Si Durou manifestaba así sus principales preocupaciones, los resultados de las visitas le pusieron en contacto con los mayores problemas de su Iglesia: el pueblo guatemalteco era fuertemente religioso, pero también negligente en el cumplimiento de las obligaciones impuestas por la Iglesia y estaba alejado de la ortodoxia; existían multitud de asociaciones y cofradias sin estatutos ni autorización arzobispal, indisciplinadas y «sin más obligaciones que las que ellos se trasmiten de unos a otros»; la falta de sacerdotes había favorecido la multiplicación de las uniones de hecho, sin matrimonio ni civil ni religioso, el desaIrollo del protestantismo y la ignorancia religiosa, y, por último, la lamentable situación económica de la Iglesia mantenía los templos en un estado ruinoso, y continuarían así durante años.

Monseñor Durou, que poco pudo hacer para resolver estos problemas, mantuvo, en términos generales, buenas relaciones con el Gobiemo y, gracias a ello, fue el primer arzobispo desde la revolución liberal que no fue expulsado del país y consiguió que se establecieran relaciones diplomáticas con la Santa Sede y que se permitiera ingresar en Guatemala a los salesianos y a los jesuitas.

La Santa Sede había demostrado su interés en la reconstrucción de la Iglesia en Guatemala, pero, a causa de su desconfianza en la capacidad de reacción del clero nacional y en su preparación, se iba a apoyar fundamentalmente en las órdenes religiosas y en las Iglesias europeas y norteamericanas.

conserva Jos informes de las visitas a Livingston (T5 63 31; 1930), Zacapa (T5 63 42A; 1930), Salamá (T5 63 125A; 1930), Santo Domingo de Cobán (T5 62 158B; 1931) y San Cristobal, Alta Verapaz (T5 62 158D; 1931). Probablemente, este archivo guarde traspapelados los restantes informes.

4 AHA T5 63 31, 23.XII.1929.

3 Entre los testimonios de esta polf́tica, ninguno es tan significativo como la carta del Nuncio Mons. Beltrami: "Con un Clero tanto insuficiente e senza formazione, dove nessumo insegna, nessuno predica, nessuno ha la minima idea di apostolato- i Padri [los jesuitas] finisco di essere l'unico lievito che possa fementare questa massa informe" (ASJ-CA 6.1 Asistencia de España P. Azcona 1942-58: 27.1.1941). Del mismo modo se explican las intenciones de Roma con respecto al Seminario de Guatemala (ASJ-CA 8.4 Guatemala: Echarri Viceprovincial: carta de Echarri a Bariain, 14.I.1952), sus deseos de encomendar un departamento de Guatemala a cada orden religiosa, con independencia de la autoridad episcopal (ASJ-CA 5.1 Autoridades ecca. Guatemala Nunciatura: carta de Azcona al Viceprovincial 16.V.1952), o sus intenciones de nombrar obispos religiosos (ASJ-CA 6.1 Asistencia de Espafia P. Azcona 1942-58: carta de Bariain a Verolino, 25.X.1952).

La Iglesia en la Encrucijada

Hispania Sacra 49 (1997) 


\section{La Iglesia, el régimen del general Ubico y la Revolución.}

Las política de entendimiento con el gobierno desarrollada por Monseñor Durou fue continuada por su sucesor, Mariano Rossell Arellano. Durante la Presidencia de Jorge Ubico, y sobre todo en sus últimos años, las relaciones entre la Iglesia y el Gobierno fueron relativamente cordiales. Monseñor Rossell reconoció en Ubico «actitudes manifiestas en favor de la Iglesia», como permitir el ingreso de la Compañía de Jesús y, sobre todo, establecer relaciones diplomáticas con la Santa Sede. Convencido de que podrían conseguirse mayores ventajas para la Iglesia, mantuvo Monseñor Rossell una «cierta cordialidad» con el Gobiemo y continuó la política de evitar conflictos, iniciada por su antecesor. Reconoció también que se detuvo la apropiación indebida de bienes de la Iglesia y que, respetando la jurisdicción eclesiástica, el Gobierno no consintió el ingreso de ningún sacerdote sin la aprobación del Arzobispado 6 .

Pero los problemas seguían existiendo. Entre 1937 y 1944 no fueron pocos los conflictos entre los sacerdotes y las autoridades políticas locales, casi siempre originados en cuestiones de propiedad, aunque no complicaron gravemente las relaciones entre la Iglesia y el Gobierno, que incluso, en ocasiones, resolvió los conflictos en favor de aquella?.

Por otra parte, la carestía de clero estuvo muy lejos de resolverse. Todo hace pensar que en este periodo el Arzobispo fue, si no la única, la principal vía para solicitar al Gobierno el ingreso de sacerdotes. Según los datos del Archivo Histórico Arquidiocesano, ingresaron únicamente doce sacerdotes nuevos en quince años, una cifra muy insuficiente para resolver el problema ${ }^{8}$. Además,

6 AHA T3 48; Informe polftico, 1949.

7 AHA T1 68: 334, 21 y 29.VII.1942.

8 Estos datos proceden del análisis de todas las solicitudes tramitadas por la Curia que se conservan en el AHA. Las solicitudes de permiso de ingreso en Guatemala para religiosos extranjeros que, de una forma u otra, fueron atendidas por la Curia Arzobispal entre 1930 y 1960 , permiten realizar algunas afirmaciones. Pero es necesario tener en cuenta un hecho fundamental: el estado del Archivo Arzobispal no permite afirmar que las solicitudes conservadas sean todas las tramitadas en su dia, por lo que las cifras sólo pueden tener valor como orientación. En resumen los datos son estos:

Entre 1930 y la Revolución de Octubre: Se concedieron 100 permisos: 61 a religiosos, 12 a sacerdotes seculares, 15 a sacerdotes de los que se ignora su condición de secular o regular, 5 a seminaristas que venfan a continuar sus estudios, 3 a religiosas y 4 permisos colectivos para asistir a algunas celebraciones de tipo religioso. Se concedieron 45 permisos no superiores a tres meses, otros 45 superiores y 10 por tiempo desconocido. De los 45 permisos por más de tres meses, se concedieron 27 a espafioles, 8 a salvadoreños, 3 a italianos, 2 a estadounidenses, uno a un guatemalteco y otro a un puertorriqueffo. Ignoramos la nacionalidad de dos de las personas a las que se les concedio este tipo de permiso. De las 45 personas que pudieron ingnesar por un periodo superior a los tres meses, solo 24 lo hicieron sin la condición de sustituir a otro, fallecido o que hubiera abandonado Guatemala, y de estos 24, solo 12 cran sacerdotes. 
en repetidas ocasiones el Arzobispado tuvo que rechazar los servicios de sacerdotes por no conseguir su ingreso ${ }^{9}$, y los jesuitas, por su parte, propusieron el ingreso de algunos guatemaltecos y temieron ausentarse temporalmente del país y no poder regresar ${ }^{\ddagger 0}$.

Entre la Revolución y la caída de Arbenz: Se concedieron 10 permisos: 6 a religiosos, 1 a un sacerdote secular, 2 a sacerdotes de los que se ignora su condición de seculares o regulares, y 1 colectivo. 7 eran permisos de estancia superior a tres meses y 3 inferiores. De los 7 que ingresaron por un tiempo superior a tres meses, 4 eran españoles, 2 estadounidenses y 1 alemán. 5 ingresaron con la condición de sustituir a otras personas, y cinco eran sacerdotes.

Después de la Liberacion: Se concedieron 114 permisos: 79 a sacerdotes, 33 a religiosas y 5 a hermanos religiosos. De los 79 Padres, aparte de cuatro sobre los que ignoramos su nacionalidad, 30 eran españoles, 20 estadounidenses, 8 holandeses, 5 italianos, 4 mexicanos, 4 belgas y 2 salvadoreños. En 32 de los permisos se señala su condición de sacerdotes regulares.

Partiendo de todos estos datos puede afirmarse.

a) Las relaciones de "cierta cordialidad" entre la Iglesia y el Gobiemo de Ubico no significaron en ningún modo la apertura de las fronteras al clero extranjero, cuando durante todo este periodo sólo 12 nuevos sacerdotes ingresaron en la República por medio de una solicitud del Arzobispado, que era, sin lugar a dudas, el principal interlocutor ante el Gobierno de Ubico.

b) En este periodo el dominio del clero español entre los sacerdotes extranjeros es indiscutible, un $60 \%$ de los extranjeros que ingresaron en Guatemala eran españoles, mientras que después de la Liberación, pese a que continúan predominando, sólo un $37,9 \%$ eran españoles.

c) Parece ser que las relaciones entre el Arzobispado y el Gobierno se rompen definitivamente en 1947, coincidiendo con la clausura de Radio Pax, pero otras instituciones si tramitarán ante el Gobierno algunos permisos, como prueban las numerosas solicitudes que, tras la caída de Arbenz, se realizarán para normalizar la situación de muchos extranjeros. No puede afirmarse pese a todo que el Gobierno permitiera con cierta libertad el ingreso de religiosos extranjeros. El Archivo provincial jesuita nos indica lo contrario: las numerosas dificultades puestas por el Gobierno y las trampas, fundarnentalmente basadas en esconder la condición de religiosos, utilizadas para superar estas dificultades.

d) Ś́lo con la caída de Arbenz las fronteras guatemaltecas se abrirán al clero extranjero, que ernpezará a multiplicarse tanto en su número, como en su procedencia nacional y en la diversidad de las órdenes y congregaciones a las que pertenezca. Por otra parte, tras un primer periodo en el que parece que la Curia Arzobispal es el principal, o quizás el único interlocutor ante el Gobierno de Castillo Armas -hay que tener en cuenta las pésimas relaciones que siempre mantuvo éste con el Nuncio-, empezarán a ingresar religiosos en Guatemala incluso a espaldas del Arzobispado, como prueban el inmenso número de religiosos que aparecen en los Datos Estadisticos de la Provincia Ecca. de Guatemala de 1959-60 (AHA s.c.), de los cuales no se tiene información de su ingreso en el Archivo Arzobispal, y el hecho de que las autoridades arzobispales tengan que pedir al Gobierno que les informe sobre los religiosos que entran en la República (AHA Oficios: 241, VIII.1955).

9 AHA T6 60: 22.II, 17.III y 26.V.1933, y Oficios: 209, 7.V.1937, 30 y 207, 27.I y 25.VIII. 1939,414 y 529, 9.VI y 21. IX.1942.

10 ASJ-CA 8.4 Guatemala: Guatemala Seminario 1938 ... Iriarte Viceprovincial: carta de Iriarte a Ponsol, 8.VI.1939, ASJ-CA 11.3 Sujetos de otras Provincias: P. Sáenz de Santamaría: carta de Ponsol a Santamaría, 22.I.1939.

La Iglesia en la Encrucijada Hispania Sacra 49 (1997) 
Los choques con el Gobiemo, de mayor o menor gravedad, siguieron existiendo:

- el P. Eliseo González fue sometido a Consejo de Guerra y encarcelado, «por haberle dirigido una carta privada al gobernante, en la que le pintaba la situación miserable de las familias de algunos feligreses suyos, a quienes por una ley de Vialidad, se les obligaba a trabajar gratuitamente en los caminos, durante ocho días y sin más alimentación, que la que podían llevar consigo, tiempo que con frecuencia más que regular y por el servilismo y crueldad de muchos Jefes Políticos (Gobernadores Departamentales), era ampliado en las mismas condiciones miserables, a mucho más aún»; sólo después de la intercesión del Arzobispo, se suspendió la condena y se expatrió al sacerdote ${ }^{1 \mathrm{l}}$;

- se prohibió el ingreso en la República de Monseñor Víctor Sanabria, Arzobispo de San José de Costa Rica, acusándole de comunista, contra lo que reaccionó Verbum ${ }^{12}$;

- la Carta Pastoral de Monseñor Rossell sobre la Indisolubilidad del Matrimonio Cristiano provocó reacciones críticas en los sectores políticos gubernamentales.

Pese a que los motivos de conflicto no habían desaparecido, la Iglesia trató de mantener relaciones cordiales con el Gobierno ${ }^{13}$, por creer Rossell que de esta forma se multiplicarían las ventajas de la Iglesia, por indicación de la Santa Sede, que quería evitar a toda costa una nueva expulsión del Arzobispo, y por una cierta coincidencia ideológica, en su oposición al comunismo y en su simpatía por el régimen de Franco ${ }^{14}$, coincidencia que tendría consecuencias muy negativas para la Iglesia una vez triunfase la Revolución.

11 AHA T3 48: Informe político, 1949.

12 Verbum: 16 y 23.1.1944 y Nuestro Diario: 20,24 y 27.XII. 1943 y 19.I.1944. Ricardo BLANCO SEGURA, Monseñor Sanabria. Apuntes biográficos, San Jose, 1971, aparte de sus propias opiniones, recoge integramente la «Declaración de Monseñor Sanabría con motivo de habersele impedido entrar en Guatemala», pp. 343-6.

13 AHA Oficios: 95, 2.III.2937, felicitación al General Roderico Anzueto por su nombramiento como Ministro; AHA Oficios: 229, 15.V.1937, agradecimiento por el regalo del libro Seis años de Gobierno presidido por el General Ubico; AHA T1 69: 86-90: invitaciones de altos funcionarios a la Consagración Episcopal de Rossell; AHA Oficios: 366A, 1941, invitación a varios jerarcas de la Iglesia a la inauguración de la Constituyente; etc.

14 AHA Oficios: 304, 10.IX.1938; AHA T1 70: 29.VIIJ.1941 y Oficios: 2.IX.1941; ASJ-CA 8.4 Guatemala: Guatemala Seminario 1938 ... Iriarte Viceprovincial: carta de Iriarte a Ponsol 16.1.1942. La correspondencia mantenida entre la Embajada de Ia Gran Bretaria, el Gobiemo y el Arzobispado sobre el problema del "clero falangista" indica, aparte de que para la Embajada inglesa este problema verdaderamente no tenía importancia, la existencia de un ambiente político generalizado que identificaba al clero espantol con el régimen de Franco y que permitiria, en su momento, acusar a aquel de múltiples conspiraciones. Muchos compartieron el convencimiento de que existía una estrecha rela- 
De todas formas, la rivalidad en ningún modo desapareció y la Iglesia tampoco contó con unos requisitos mínimos de libertad, como prueba una comparación de la revista Verbum entre 1942 y 1944 -preocupada por el problema de las vocaciones, la educación, el protestantismo y el comunismo, y con alguna mención a la existencia de una legislación restrictiva para la Iglesia - y la misma revista después de la Revolución, cuando pudo ampliar sus intereses, sus agresividad y sus reivindicaciones. Pero, a costa del silencio, la Iglesia consiguió del Gobierno de Ubico unos primeros gestos de apertura. La gran transformación se lograría con una actitud nueva, muy alejada del silencio.

Una vez iniciado el movimiento para derrocar a Ubico, la Iglesia se identific6 con estos anhelos populares y, aunque con prudencia, participó en los acontecimientos: Verbum inmediatamente aplaudió la caída de Ubico, señalando los grandes problemas con los que se enfrentaba Guatemala, la situación de los obreros y los campesinos y el problema educativo, y manifestó su convicción de que el catolicismo no podía permanecer al margen en esos momentos ${ }^{15}$; con anterioridad Rossell se había comportado con heró́smo, asistiendo a los heridos en las manifestaciones reprimidas violentamente por la policia ${ }^{16} \mathrm{y}$ había rechazado las peticiones del Gobierno para apaciguar a los desconten$\operatorname{tos}^{17}$, y el director y los redactores de Verbum habían firmado el «manifiesto de los $311 »^{18}$.

Diversos sectores revolucionarios reconocieron y agradecieron estos hechos y el Gobierno, cuando a finales de 1945 fue sustituido el Nuncio Apostólico, le concedió la Orden del Quetzal, en reconocimiento por su actuación en los momentos de mayor peligro de la Revolución ${ }^{19}$. Pero tampoco faltaron las críticas $^{20}$. Los esfuerzos por distanciarse de Ubico y la actuación de Rossell y

ción entre el clero español y el falangismo. El comportamiento, más ruidoso que efectivo, de algunos sacerdotes y grupos de españoles ayudaron a suponerlo, aunque en ningún momento tuvieron estas actitudes la más mínima importancia; así lo prueba el informe enviado a España por Francisco López. Escobar, Encargado de Negocios en Guatemala, cuando el Gobiemo del General Ubico decreto Decreto 2241, 25.V.1939- la prohibición de cualquier actividad política realizada por grupos o individuos extranjeros; archivo del ministerio de asuntos exteriores (Madrid): Asunt: Guatemala; Leg. R. 4003, Núm. 4: 28.V.1939. También pueden consultarse los Fondos del Gobierno de la República en el exilio; Sig. M. 442: Despachos enviados al Ministerio de Estado por la Embajada de Guatemala 18.XI, 14.XIl.1945.

Is Verbum: 19.VII.1944, ed.

16 El Imparcial: 16.VII.1944 y MEjÍA, Medando El movimiento obrero en la Revolución de Octubre, Guatemala, 1949, p. 69.

17 AHA T3 48: Informe políico, 1949.

18 EsTrada, A. Datos para ..., ob. cit., vol. III, p. 563.

19 El Imparcial: 16.VII.1944, M. Mejia, op. cit, Verbum: 9.XI.1945.

20 Por orden del Gobierno se suspendio la misa por Maria Chinchilla en la Catedral, y algunos sectores revolucionarios acusaron de esta decisión a la Iglesia, Verbum: 16. VII.1944.

La Iglesia en la Encrucijada

Hispania Sacra 49 (1997) 
algunos sacerdotes una vez iniciada la Revolución no fueron suficientes: los revolucionarios habían recibido una formación totalmente ajena a los ideales católicos; el clero extranjero, español en su mayoría, que había ingresado en los últimos años del régimen de Ubico no ayudó a limar asperezas, si bien la mayoría de las acusaciones que se hicieron contra él no tenían ningún fundamento y existen pruebas de la falsedad de muchas, era indiscutible su simpatía hacia el régimen de Franco; y la Iglesia fue incapaz de imprimir suficiente énfasis en los problemas sociales del país y, en parte por su falta de recursos económicos y humanos y por su lenta reacción, fue desplazada de cualquier función en el nuevo régimen.

Componentes $e$ ideales revolucionarios: La Asamblea Nacional Constituyente de 1945 y sus resultados.

Derrotado el último de los dictadores liberales, la Iglesia creyó que para ella también se había iniciado una nueva etapa ${ }^{21}$; pronto surgio la desilusión.

Las discusiones de la Asamblea Nacional Constituyente de 1945 muestran con claridad el enfrentamiento radical existente entre los planteamientos de la Iglesia católica y los ideales revolucionarios. La Constituyente de 1945 pretendió establecer las bases de un sistema político democrático que permitiera el desarrollo económico y la integración social de Guatemala. La mentalidad revolucionaria guatemalteca tiene su origen en una experiencia de oposición - asentada sobre los posos ideológicos del liberalismo decimonono- contra los regímenes dictatoriales de 1920 y 1940 , cuyos protagonistas, muchos desde el exilio, entraron en contacto con diversos países y grupos de personas identificados, de un modo u otro, con la lucha antifascista y se dejaron influir por la propaganda bélica aliada (que no pudo ser censurada por Ubico) y por el prestigio y la influencia ganados por la Unión Soviética y el comunismo a raíz de su participación en la Guerra Mundial22.

Las medidas nacidas de esta ideología llevaron a la oposición a Ia Iglesia católica: además de los resultados de la Constituyente, se abrieron relaciones diplomáticas con la Unión Soviética y se rompieron con Franco, se dificultó el

21 Eso indican los editoriales de Verbum; la invocación permanente de los revolucionarios a las Cuatro Libertades o las nuevas actividades que iniciaron, y que de ningún modo habrían podido desarrollar con Ubico, los neligiosos, por ejemplo, y muy significativamente, la fundación del Secretariado Social Rerum Novarum y de Acción Social Cristiana.

22 GÓMEZ DÍEZ, F. J. “La política guatemalteca en los origenes de la 'Década Revolucionaria': la Asamblea Constituyente de 1945", Revista de Indias, LV;203 (Madrid, 1995) 127-47, y "La Revolución Guatemaiteca de 1944: la Asamblea Nacional Constituyente y la mentalidad revolucionaria", Estudios de Historia Social y Económica de Amêrica, 13 (Alcalá, 1996). 
ingreso del clero extranjero y, a lo largo de toda la Década, se tomaron diversas decisiones contrarias a los intereses de la Iglesia.

En la línea en la que se pronunciaron los constituyentes y la inmensa mayoría de la prensa en aquellos momentos, lo harían también los dos Presidentes de la Década Revolucionaria: Juan José Arévalo y Jacobo Arbenz ${ }^{23}$.

Una vez establecida la Asamblea Constituyente los sectores católicos se dieron cuenta de que no tenían ninguna posibilidad de sacar adelante sus peticiones si las dejaban únicamente en manos de los diputados, e intentaron, con muy poco éxito y creo que escaso convencimiento, presionar a la Asamblea por medio de la opinión pública, pero, la debilidad de este movimiento y la oposición general de la prensa - a excepción de los semanarios católicos y de La Hora- y de todos los grupos revolucionarios organizados, impidieron que las reivindicaciones de la Iglesia llegaran realmente a discutirse en la Asamblea, donde, los escasos representantes católicos a muy poco se atrevieron.

La Iglesia y sus partidarios solicitaban personalidad jurídica, para poseer bienes, que se facilitara el ingreso de sacerdotes extranjeros y la posibilidad de enseñar libremente su doctrina social e intervenir en las asociaciones laborales. Invocaban las Cuatro Libertades, la legislación de las naciones aliadas occidentales y el hecho de que la mayoría del pueblo guatemalteco era católica. Su intención era conseguir que la Iglesia pudiera desarrollar plenamente su labor, religiosa, social y educativa ${ }^{24}$.

Los problemas comenzaron con las reacciones contrarias a la participación de un grupo de militares en un acto religioso el 24 de diciembre de 1944. Respondiendo a estas reacciones, El Imparcial tuvo ocasión de opinar sobre el tema: «no hay para que hurgar ni armar fantasmas que después nos asusten, o que, en mala hora, puedan acarrear desagradables consecuencias. Las luchas de Iglesia y Estado deben tenerse por canceladas; no hay ni siquiera que revisar el proceso de ellas, porque se orillaría el riesgo de revivir penosas heridas

23 ARÉvalo, Juan José. Escritos políticos y discursos, La Habana, 1953; "Parte expositiva de la Memoria de la Secretaria de Relaciones Exteriores, correspondiente al año de 1944, presentada a la Asamblea Legislativa en sus sesiones ordinarias de 1945", Diario de Centroamérica: 21.VII.1945, sobre las medidas tomadas en apoyo de los aliados durante la II Guerra Mundial; "Informe del Ciudadano Presidente de la República, doctor Juan José Arévalo, al Congreso Nacional en la inauguración de su primer periodo de sesiones ordinarias del año 1946", Diario de Centroamérica: 1.III.1946, sobre las conspiraciones de la reacción; así como todas las intervenciones de Arévalo en defensa de sus repetidas suspensiones de garantías. Arbenz, compartió todos estos planteamientos y aradió una abierta defensa de los comunistas y un fuerte sentido social, que en Arevalo y en los constituyentes de 1945 no se encontraba tan claro; "Informe del Ciudadano Presidente de la República, Coronel Jacobo Arbenz Guzmán, al Congreso Nacional en su primer periodo de sesiones ordinarias de 1954", Diario de Centroamérica: 5.IIl.1954.

24 Accion Social Cristiana: 28.I, 1, 8 y 15. II y 22.IIl.1945.

La Iglesia en la Encrucijada

Hispania Sacra 49 (1997) 
que el tiempo y el buen sentido han procurado cicatrizar». Verbum, negando también la existencia de un problema religioso, solicitó libertad para la Iglesia indicando que se la daban las naciones democráticas y que la mayoría del pueblo era católica. Nuestro Diario creía en la existencia de un problema clerical y negaba el problema religioso; la mayoría del pueblo guatemalteco era católica, pero no clerical. Al contrario que en la Iglesia evangélica, donde había una gran identidad entre el clero y los fieles, esta identidad no existía en la Iglesia católica, y su falta había permitido el desartollo de este problema. Pese a todo, no era grave: el clero político sólo contaba con el apoyo del falangismo internacional, que podría eliminarse rompiendo las relaciones con Franco, pero carecía del menor apoyo popular. En definitiva, para este diario la Revolución Liberal había alcanzado dos grandes conquistas: el «Estado laico» y las «escuelas democráticas», y en su defensa estaba quedando claro donde se encontraba la reacción. El lmparcial volvió a insistir en sus planteamientos y pidí́ a la Iglesia que respetase las opiniones de la administración y no se metiera en asuntos que no eran de su competencia. Sólo La Hora defendió al clero y criticó a los que temían a la Iglesia ${ }^{25}$.

La Iglesia hizo públicas sus reivindicaciones: «una libertad religiosa sin cortapisas, ni regateos en el aspecto doctrinal, ni en el ejercicio del culto"; que no se pusieran trabas «a las asociaciones culturales, sociales y de Acción Católica» y que la misión docente de la Iglesia no se obstaculizase, garantizando la libertad frente al monopolio de parte estatal; mientras, afirmaba no querer privilegios, sino sólo la paridad de garantías con los otros credos y la no intromisión del Estado en los asuntos religiosos ${ }^{26}$.

La agudización del conflicto obligó a la Junta Revolucionaria de Gobierno a hacer pública su posición ${ }^{27}$ :

* (...) la Junta ha visto con profundo disgusto que varios sectores, aunque insignifi cantes por su tamafio e importancia, malinterpretan la palabra libertad, convirtiéndola en un libertinaje y aprovechan la libertad de prensa que existe, para comenzar una labor djsociadora (...) En una genuina democracia debe existir la absoluta e irrestricta libertad de cultos como lo ha promulgado la Junta Revolucionaria de Gobiemo en el Decreto núm. 17 que créo los principios de la Revolución. Como es de conocimiento general, la mayoría de los guatemaltecos profesa el catolicismo y el gobiemo no se opone ni podría oponerse a que dicha religión desarrolle sus labores normales y sus funciones de acuerdo con sus principios religiosos. Sin embargo, no permitirá bajo ningún concepto que Ios representantes de cualquier religión intervengan en asuntos políticos (...) por estar

${ }^{25}$ El Imparcial: 28.XI.1944 y 25.I.1945; Verbum: 14 y 28.I.1945; Nuestro Diario: 17, 20 y 22.I.1945; La Hora: 25.I y I.II.1945.

26 Verbum: 4.II.1945

${ }^{27}$ El Imparcial: 24.1.1945 


\begin{abstract}
fuera de la esfera razonable de sus funciones. Por consiguiente, advierte a todos estos religiosos y a todos los que valiendose de la prensa o de publicaciones separadas, traten este asunto en una forma tendenciosa, que está dispuesta a mantener la tranguilidad del pais (...) La Junta Revolucionaria de Gobiemo al mismo tiempo, hace un Ilamamiento al pueblo advirtiéndole que no debe dejarse sorprender, ya que estos elementos tratan de crear un estado de intranquilidad con respecto a futuras supuestas persecuciones religiosas, así como hacerles creer que hay una intolerancia por parte de los elementos de gobiemo para ver el desarrollo normal de todas las religiones que en una democracia tienen derecho a actuar (...) $)$
\end{abstract}

Una declaración como ésta recortaba muchísimo las posibilidades de la Iglesia, que fue colocada, en pocos días, por la prensa, el Gobierno --integrado por el ejército- y el Congreso en el bando de la reacción. Acción Social Cristiana fue categórica: «se ve suficientemente claro que se quiere llevar a Guatemala a un cisma gravísimo», «los católicos han intentado hacer valer sus derechos con los medios que en toda democracia son permitidos; pero, a sus razones y argumentos, se ha respondido con el insulto, con escapadas por la tangente (...) se les ha querido señalar como perturbadores». Cuando la Comisión Constituyente de los Quince iniciaba sus discusiones sobre el tema religioso, aún había tiempo, según el semanario, de rectificar ${ }^{28}$.

La Asamblea Legislativa también se pronunció. Al llegar un telegrama, desde El Progreso, que pedía al Presidente de la Legislativa, Manuel Galich, abstenerse de promulgar leyes contrarias al catolicismo, éste llamó la atención a los Representantes sobre el problema que, por la agitación que estaba causando, podía ser peligroso. Se entabló una discusión, en la que Zea González propuso que la Legislativa manifestara su posición en una declaración a la prensa; Salguero acusó de esta agitación al falangismo y piđió que se aplicara contra él mano dura; en la misma línea se pronunció Guerra; mientras España y Fortuny acusaban a la reacción de fomentar los conflictos religiosos. Cuando Bauer Paíz trató de salir en defensa de los católicos no pudo hablar, interrumpido en tres ocasiones por una acalorada Asamblea. De este modo, redactaron una declaración en la que un nuevo organismo del Estado se oponía a las pretensiones de la Iglesia ${ }^{29}$.

La discusión del problema llegó a la Constituyente por dos vías: la tímida defensa de las posturas católicas realizadas por algunos Representantes y los diversos manifiestos y cartas enviados al Congreso ${ }^{30}$. El Arzobispo hizo públi-

2B Acción Social Cristiana: 1.1I.1945

29 Sesiones 50 y 51, 3 y 5.Il.1945, Diario de Centroamérica: 13.IV.1945; El Imparcial: 5 y 6.II.1945.

30 La Asamblea recibió, en torno a este tema, las siguientes cartas: petición del Arzobispado; memorial del 8.11.1945, con 354 hojas de firmas procedentes de Guatemala, Antigua, Santa Lucia 
ca una circular, leída en las iglesias el domingo 4 de febrero, donde solicitaba de los católicos que, igual que habían luchado contra Ubico, lo hicieran ahora, en favor de los derechos de la Iglesia, pero usando de las mejores maneras, sin amenazar el orden público, ni sembrar la discordia entre los guatemaltecos. Días después publicó una Pastoral, donde, tras recordar la abrumadora mayoría católica de Guatemala, defendió que la sociedad debía fundarse no en la «separación sistemática», sino en la "concordia y armonía» entre la Iglesia y el Estado y, por primera vez, habló de «vientos de persecución»"31.

La posición de la Iglesia también se manifestó por medio de una carta del Episcopado y un memorial firmado por un numeroso grupo de católicos. Los Obispos prudentemente se limitaron a manifestar la satisfacción que les produjo el Decreto 17 de la Junta Revolucionaria ${ }^{32}$, que entraño la promesa de libertad religiosa; el sufrimiento de la Iglesia católica en los últimos 70 años y la sorpresa al descubrir, frente a una Iglesia que no pedía privilegios, la tendencia restrictiva de la Constituyente.

Por su parte, ef memorial, que coincidía plenamente con las reivindicaciones de Verbum y Acción Social Cristiana, señaló el alto porcentaje de católicos con los que contaba Guatemala, la distinción entre la separación de la Iglesia y el Estado y la libertad de cultos, el carácter del catolicismo como columna sostenedora de la nacionalidad y el ejemplo de libertad religiosa que daba Estados Unidos, y solicitó «la libertad religiosa sin restricción alguna», «la personería jurídica para la Iglesia católica, incluyendo el derecho de la Iglesia para adquirir y poseer bienes», «la libertad de asociación sin restricciones para los católicos, tanto religiosos como seglares» y «la libertad de enseñanza».

Pero, como he analizado en otra ocasión ${ }^{33}$, estas peticiones no fueron atendidas por los representantes.

Cotzumalguapa, Retalhuleu, Quetzaltenango y El Quiché; un telegrama, con 581 firmas, 9.II.1945, Guatemala; memorial firmado, cntre otros, por el director de Acción Social Cristiana, 9.Il.1945; memorial dirigido al diputado Feliciano Fuentes Alvarado, 11.II.1945; memorial, 11.II.1945, con ccho hojas de firmas, y memorial, 8.III.1945, pidiendo la revisión de los artículos, firmado entre otros por Du Teil y Alberto Rosales. Archivo del congreso de la república (Guatemala): Asamblea Nacional Constituyente 1945, Correspondencia núm. 2 y Asuntos relacionados con la religión.

3 Verbum: 11.II.1945; Mons. Rossell, "Circular a los fieles" y Carta Pastoral acerca de la obra de la Iglesia católica, 22.II.1945.

32 Los sectores católicos recurrieron repetidas veces a la autoridad de la Junta Revolucionaria de Gobiemo, en un esfuerzo por presionar al Congreso; Verbum: 15.II.1945: "Estamos con la Junta Revolucionaria (...) Una cosa es para los catolicos la Junta Revolucionaria de Gobiemo y oura el proceder de ciertos constituyentes".

33 GómEZ DíEZ, F. J. «La política guatemalteca...», ob. cit. Se ha defendido - GLEIJESES, Piero. Shattered Hope. The Guatemalan Revolution and the United States 1944-1954, New Jersey, 1992, p. 49 - que la Constituyente de 1945 represento una superación considerable de las posturas anticlericales del liberalismo guatemalteco, apoyando tal afirmación en la legalización de las procesiones y 
Mientras para los revolucionarios se había cerrado definitivamente un capítulo, todo lo contrario había sucedido para los grupos católicos: un fraude a la libertad, un atentado a la Carta del Atlántico, el abuso de una minoría; la reforma constitucional se convirtió en una reivindicación permanente ${ }^{34}$.

Tanto por los resultados de la Constituyente, como por las dificultades puestas al ingreso del clero extranjero y los planteamientos políticos del nuevo régimen, nada había cambiado en esencia con respecto al problema religioso. Otras dos decisiones agravaron el distanciamiento entre la Iglesia y la Revolución: la ruptura con Franco y la apertura de relaciones con la Unión Soviética; decisiones avaladas por la unanimidad de los sectores revolucionarios, que, al contrario que la Iglesia, no veían peligro en el comunismo, sino en la infiltración falangista auspiciada por Franco.

\section{PROBLEMAS LOCALES Y PARROQUIALES DE LA IGLESIA EN GUATEMALA DURANTE LA DÉCADA REVOLUCIONARIA}

Si el punto de partida de la oposición de la Iglesia a la política de los gobiernos de Arévalo y Arbenz se encuentra en la Asamblea Nacional Constituyente de 1945, otro factor condiciona todo el proceso: la Década Revolucionaria representa un proceso de movilización política nacional que no había tenido lugar nunca hasta entonces, que alarma muy considerablemente a una Iglesia débil y marginada por los sectores políticos gobernantes. Esta movilización y las reacciones que provoca se observan claramente en los conflictos que se desarrollan entre el pueblo católico, la jerarquía eclesiástica y las instituciones de poder local ${ }^{35}$.

Considerando las visitas pastorales de Monseñor Durou y el conjunto de su actuación episcopal, no existen motivos para pensar que los conflictos desarrollados durante su gobierno sean substancialmente distintos a los de la época de Rossell. El único factor que cambió en estos años fúe la mejoría de las rela-

\footnotetext{
en el hecho de que el tema religioso fue discutido abiertamente en la Asamblea. Pero, tanto el hecho de que las procesiones nunca habian dejado de celebrarse, como las grandes diferencias entre los deseos de la Iglesia, sus peticiones, las propuestas que los denominados diputados católicos se atrevieron a hacer y las resoluciones definitivas de la Asamblea, obligan a negar tal conclusión.

${ }^{34}$ Acción Social Cristiana: 8 y 29.1Il.1945; Verbum: 9 y 15.II.1947; Nuestro Diario: 16.H.1945.

35 En mi tesis doctoral ("El reformismo jesuítico en Guatemala durante la época de la Guerra Fría (1945-1970)", Facultad de Geografta e Historia, Universidad Complutense de Madrid, 6.VI.1994) he recogido con detalle todos los conflictos desarrollados entre las autoridades eclesiásticas, las asociaciones religiosas (cofradias, hermandades, comités para la reconstrucción de los templos, etc.) y las autoridades civiles locales, desde 1937 a 1954. En esta ocasión plantearé, brevemente, las conclusiones de ese anślisis.
}

\footnotetext{
La Iglesia en la Encrucijada
}

Hispania Sacra 49 (1997) 
ciones con el Gobierno, pero, ni cambiaron las estructuras internas de la Iglesia, ni se multiplicó en número de sacerdotes, ni tampoco sufrí la sociedad guatemalteca cambios importantes. Por estos motivos, creo suficientemente ilustrativo iniciar este análisis en 1937, cuando comienzan a tomar cuerpo las reformas de Monseñor Durou.

Tanto la información del Archivo de la Curia Arzobispal, como numerosos estudios antropológicos muestran la coexistencia en los conflictos que a nivel local se entablan entre los pártocos, las cofradías y las autoridades políticas locales de factores de origen local con otros de origen nacional, así como elementos de rivalidad religiosa y profana ${ }^{36}$; pero, lo que ahora me interesa es la importancia de estos conflictos para explicar la actuación de la Iglesia, en un contexto intelectual marcado por el conflicto entre el catolicismo y sus perseguidores.

\section{El punto de partida: los conflictos anteriores a la Revolución de 1944}

Antes de la Revolución de Octubre de 1944, las relaciones entre la jerarquía eclesiástica, el pueblo católico y el poder político local estuvieron marcadas por varios elementos:

$1^{\circ}$.- Una fuerte conflictividad, tanto entre los sacerdotes y la autoridad civil, como entre aquellos y las cofradías y hermandades. Con respecto a las relaciones con las autoridades locales, aparte de algunos casos surgidos por el comportamiento abiertamente anticatólico de algunos intendentes y Jefes Locales ${ }^{37}$ y algunas intromisiones de importancia relativamente escasa ${ }^{38}$, los conflictos surgieron en torno al problema de la propiedad de la Iglesia: intentos por controlar las alcancías de las Iglesias ${ }^{39}$, usurpaciones y utilizaciones indebidas de las casas parroquiale $\mathrm{s}^{40} \mathrm{y}$ usurpaciones y aprovechamientos indebidos de predios ${ }^{41}$; es decir, los problemas surgen fundamentalmente por la incapacidad de la Iglesia católica para garantizarse el control de sus bienes, porque, al carecer de personalidad jurídica, no podía como tal poseerlos, y las maniobras de las

36 Un análisis de la variedad e importancia de estos conflictos durante la Decada Revolucionaria puede encontrarse en Jim HANDY, Revolution in the Countryside. Rural Conflict and Agrarian Reform in Guatemala, 1944 - 1954, University of North Carolina Press, Chapel Hill and London, 1994.

37 AHA T1 69: 217, 27.IX.1940, T2 67: 26, 17.I.1941, y T1 69: 350, 25.X.1941, S. José Palencia

38 AHA Oficios: 148, 28.II.1942, y T1 68: 170, Mataquescuintla.

${ }^{39}$ AHA T6 66: 214, 28.VIII.1937; T6 65: 254, 1.X.1937, Guazacapán; Oficios: 422, 5.X.1937; Oficios: 287, 18.VIII.1939, Santiago Sacatepéquez; T1 69: 5, 4.I.1940, Sta. Maria Sumpango; T1 69: 10, 7.I.1940, Sta. María Cauqué; T1 69: 217, 27.1X.1940, T2 67: 26, 17.I.1941, S. José Palencia.

40 AHA T6 66: 33, 7.II.1938, San Antonio Suchitepéquez.

4I AHA T1 68: 172, 14.IV.1942, Sta Lucia Cotzumalguapa. 
autoridades locales para beneficiarse de esta incapacidad. Pese a todo, Monseñor Rossell reconoció que el Gobierno había tratado de poner fin a estas violaciones ${ }^{42}$.

Por otra parte, la falta de sacerdotes había fortalecido la estructura políticoreligiosa de las cofradías y afectado tanto a la ortodoxia, como al concepto de jerarquía eclesiástica, generalizando la creencia de que el sacerdote era un servidor de la autoridad de los principales. La Iglesia, para recuperar su control sobre las comunidades, negó la autoridad de las cofradías y provocó la reacción de éstas. La conflictividad con cofradías, hermandades y otras asociaciones de fieles, más o menos permanentes -comités pro-reconstrucción, comités pro-fiestas, etc.-, mucho más frecuente y aguda que la mantenida con las autoridades políticas, se estableció en torno a los intentos de la Curia por fortalecer la autoridad del clero, los esfuerzos por purificar de costumbres paganas la religión popular y los deseos de controlar los ingresos de las iglesias. Es posible configurar un esquema de las causas de estos conflictos:

- Esfuerzos por controlar los bienes de la Iglesia: los objetos de culto, los ingresos para la reconstrucción de los templos y las limosnas ${ }^{43}$.

- Esfuerzos por fortalecer la autoridad del clero: haciéndoselo ver a los fieles con escritos del Gobierno Eclesiástico, debilitando o rechazando asociaciones, no aceptando sus estatutos o intentando modificar sus directivas, 0 , incluso, apelando a la intervención de la autoridad civil ${ }^{44}$. La intervención de la autoridad civil fue un recurso muy poco utilizado (sólo se dieron dos casos) y en ningún modo deseable para la Iglesia, que nunca estuvo de acuerdo con la intromisión de elementos civiles si había sido solicitada por los fieles y prefirió no mezclarse en las cuestiones del gobierno civil. Por otra parte, al contrario de lo que sucederá en épocas posteriores, fue la Iglesia la que, de considerarlo necesario, informó al poder civil de las protestas de tipo religioso de los fieles ${ }^{45}$.

42 Informe Poltitico, AHA T3 48, 1949.

43 AHA T6 66: 232, 25.IX.1938, Santa Ana Chimaltenango; T6 61: 118, 26.VI.1939, Sto. Domingo Xenacoj; Oficios: 325, 7.IX.1939, Sta. Rosa Huehuetenango; Oficios; 475, 23.XII.1939, Guazacapăn; T6 66: 27.XII.1939, Samayoa; T1 70: 60 y 61, 3.111.1941, Sto. Domingo Xenacoj; T1 70: 9.1II.1941, Chiquimulilla; T1 68: 149, 26.III.1942, Antigua; T1 68: 273, 4.VI.1942, Ciudad Vieja; T1 66: 24, 16.I.1943. Antigua: T1 65: 278, 24.VII.1944, Antigua.

44 AHA Oficios: 176, 20.1V.2937, Mazatenango; Oficios: 68, 24.11.1938; T6 66: 3.VIII.1938, Nueva Santa Rosa; T6 66: 30, 7.II.1938, San Miguel Dueñas; Oficios: 73, 28.II.1938, Tecpán; T6 66: 1.XII.1938, Quetzaltepeque; Oficios: 200, 26.VI.1939, San Felipe; Oficios: 372-3 6.X.1939, Sta. Elena Barillas; Oficios: 193, 30.V1941, S. Martin Jilotepeque.

45 AHA Oficios: 107, 10.III.1937, Barbarena; T1 67: 93, 17.II.1942, Oficios: 18.II.1942, y T1 68: 113, 1.III.1942, S. Martin Jilotepeque; T1 68: 131, 15.IIl.1942, S. Juan Sacatepequez.

La Iglesia en la Encrucijada

Hispania Sacra 49 (1997) 
Pese a todos los esfuerzos, la debilidad de la autoridad sacerdotal era muy grande y se manifestó en múltiples ocasiones ${ }^{46}$.

- Esfuerzos por suprimir todas las costumbres profanas de la religiosidad popular: las borracheras; la conversión de las festividades religiosas en ferias, con mercado, conciertos de marimba, etc.; alargar las procesiones hasta altas horas de la noche; suprimir todas las incorrecciones, fundamentalmente en Semana Santa, que en ocasiones, según no pocos sacerdotes, las cofradías convertían en «ferias escandalosas»; separar, en una palabra, en las festividades todo lo religioso de lo profano ${ }^{47}$.

Todas las cartas que plantean al Arzobispado el problema de las cofradias, creo que muy bien podrían resumirse en la enviada por el párroco de Chiquimula, que recoge brevemente la imagen que de estas asociaciones tenía el clero:

«Existen en esta parroquia ciertos grupos Ilamados cofradias cuyo fin principal debería ser el incremento del culto público según la liturgia y conforme al espíritu de la Iglesia. Sin embargo han degenerado de tan alta finalidad en costumbres no sólo necias y ridículas sino, en ciertos casos, hasta supersticiosas. Además, en vez de sujetarse al párroco, obedecen indicaciones de un jefe o jefes llamados "los principales" (...) Nunca, por lo menos durante mi cargo, han dado cuenta de si colectan o no limosnas y menos indican la cantidad (...) guardan objetos religiosos de diversa especie (...) Ninguno de

46 AHA T6 65: 345, 22.XII.1937, en Quetzaltepeque los vecinos solicitaron el retiro de su párroco y su sustitución por el P. Peraza; Oficios: 375, 6.1X.1937, Mataquescuintla; T1 70: 9.III.1941, en Chiquimulilla se produjo una solicitud semejante; $T 169: 387,24 . X I .1941$, un sacerdote presenta su renuncia, incapaz de controlar a su feligresía; T3 68: informe parroquial, ene-mar 1942, Los Remedios, Antigua; T1 67: 409, 8.X.1943, en Sta. Ana Chimaltenango la cofradia indigena, pese a la expresa prohibición de su párroco, realizaba todas las noches un rezado de casa en casa; T1 67: 547, 21.XII.1943, y Oficios: 724, 22.XII.1943, en Comalapa los cofrades, pese a la prohibición del sacerdote, dieron posesión al cofrade de Nuestra Señora de Guadalupe; T1 65: 98, 4.1II.1944, y T1 65: 205, 12.V.1944, en S. Agustín Sumpango también renuncí́ el párroco incapaz de controlar a su feligresía.

A7 AHA Oficios: 126, 22.III.1937, Chiquimula; Oficios: 222, 14.V.1937, Palencia; Oficios: 402, 22.IX.1937, Patzum; Oficios: 84, 26.11.1937, Recolección, Guatemala; T6 66: 199, 3.VIII.1938, S. Juan Sacatepéquez; Oficios: 118, III.1938, templo del Corazón de Jesús; Oficios: 117 y 131, 29.III y 2.IV.1938, Cruz del Milagro; Oficios: 130 y 136, 31.1II y 6.IV.1938, Nuestra Señora de los Remedios, El Calvario, Guatemala; Oficios: 406, 13.XII.1938, Escuela de Cristo, Antigua; Oficios: 210, 1.VII.1939, Mazatenango; Oficios: 478, 29.XII.1939, San Jose, Antigua; Oficios: 75, 21.II y 28.III.1939; T1 69: 215, 7 y 22-IX-1940, y Oficios: 306, 26-IX.1940, Los Remedios, Antigua; T1 67: 37, 28.1I.1941, Cruz del Milagro; T1 67: 93, 17.II.1942, Oficios: 18.II.1942 y T1 68: 113, 1.IIl.1942, S. Martín Jilotepeque; T1 68: 358, 12.VIIl.1942, S. Juan Sacatepéquez; T1 70: 615, 17.XI1.1942, Cuilapa; T1 67: 38, 22.I.1942, Cruz del Milagro; T1 70: 485, 9-X-1942, S. Miguel Dueñas; T1 70: 610, 15.XII.1942, El Calvario, Guatemala; T1 66: 33 y 166, 23.J y 14.IV.1943, S. Sebastián, Antigua; Oficios: 334, 11.VI.1943, S. Martín Jilotepeque; T1 67: 444 y Oficios: 611, 2.XI.1943, Tecpán; Oficios: 163, 5.IV.1944, Parroquia Vieja; T1 65: 148, 5.IV.1944, Chitay. 
estos grupos posee una organización jurídica a norma del Código de Derecho Canónico, Lib. II, Tit. XVIII, para constiluir una "Asociación pía" (...); la corona de plata que pesa una libra últimamente mencionađa, y que la usan para la imagen de la Virgen de Candelaria en la iglesia y luego para la fiesta de agosto se la pone el rey cristiano en el baile de moros, profanándola hasta con embriaguez del que la lleva (...) $\star^{48}$.

$2^{\circ}$.- Los esfuerzos del Gobierno Eclesiástico por mejorar la preparación y el comportamiento del clero, entre el cual se observaban muchas actitudes intransigentes - -existen casos de violencia; por ejemplo, un sacerdote propinó una bofetada a un indígena que no entendía sus preguntas-, una escasísima preparación - queda claramente de manifiesto sólo con observar el estilo o la ortografía de sus cartas-y, en raras ocasiones, comportamientos indisciplinados ${ }^{49}$.

$3^{\circ}$.- Una acuciante falta de clero, que se refleja en las numerosísimas solicitudes de sacerdotes, fijos o únicamente para las festividades locales; en los esfuerzos del Arzobispado por atender estas solicitudes, en ocasiones duplicando el trabajo de sus sacerdotes; en la gran cantidad de ocasiones en las que la Curia debe responder que le resulta imposible enviar sacerdotes ${ }^{50} \mathrm{y}$, en general, en toda la correspondencia consultada.

$4^{\circ}$.- El problema protestante, presente desde el primer momento, se caracteriza por una serie de elementos que le dieron un aspecto confuso ${ }^{51}$ : a) Acusa-

48 AHA T2 64: 143, 8.III.1946.

49 Oficios: 230, 15.V.1937, S. Sebastian, Antigua; T6 65: 253, 1.X.1937, Barbarena; Oficios: 498 y 499, 18.XI.1937, T6 65: 307, 19.XI.1937, Chimaltenango; Oficios: 427, 22.III.1938; Oficios: 149, 17.V.1939, Sumpango; Oficios: 411, 30.X.1939; Oficios: 469, 20.XII.1939, Nueva Sta. Rosa; T1 69: 10, 7.I.1940; Oficios: 287, 31.VII.1941, Patzicia; Oficios: 290, 5.VIII.1941, Comalapa; Oficios: 540, 2.X.1942, Barbarena; T1 70: 527, 1.XI.1942, Cornalapa; Oficios: 279, 12.VII.1944.

50 AHA Oficios: 231, 15.V.1937, Alotenango; Oficios: 515, 27.XI.1937, Samayac; Oficios: 80, 25.II.1939, Sta. Teresa; Oficios: 81, 25.Il.1939, Barbarena; Oficios: 17-8, 9.1.1939, Esquipulas; Oficios: 283, 13.IX.1940; T1 70: 155, 31.V.1941, T1 69: 294, 14.IX.1941, y Oficios: 524, 2.XII.1941, Patzum; T1 70: 267, 30.VIII.1941, Pochuta; T1 69: 291, 12.IX.1941, y Oficios: 25.IX.1941, Guazacapán; Oficios: 401, 26.IX.1941, Barbarena; T1 69: 26.IX.1941, Retalhuleu, Oficios: 546, 11.XII.1941, Nueva Sta. Rosa; Oficios: 36, 19.1.1942, Cabañas; T1 67: 48, 29.I.1942, Puerto Barrios; T1 67: 63, 16.II.1942, Barbarena; T1 68: 219, 9.V.1942, y Oficios: 386, 29.V.1942, Patzum; T1 68: 283, 14.V.1942, S. Felipe Reu T1 70: 500, 19.X.1942, Atescatempa; T1 70: 548, 14.X.1942, Cuilapa; T1 70: 557, 19.XI.1942, y Oficios: 588, 30.XI.1942, Mataquescuintla; T1 70: 558, 20.XI.1942, Siquimala; T1 70: 3.XI1.1942, Sta. Lucia Cotzumalguapa; T1 70: 609, 15.XII.1942, La Democracia; T1 66: 107, 26.Il.1943, El Estor; T1 66: 153, 30.III.1943, Patzicia; T1 66: 180, 21.IV.1943; T1 65: 43, 24.I.1944, S. Miguel Petapa; T1 65: 4, 3.I.1944, La Palmila, Guatemala; T1 65: 131, 25.IIt.1944. Livingston; T1 65: 356, 22.VI.1944, Ciudad Vieja; Oficios: 293 y 304, 28. VII y 5.VIII.1944, S. Pedro Sacatepéquez; T1 65: 332, 14.IX.1944, Escuintla.

51 AHA Oficios: 126, 22.III.1937, Chiquimula; Oficios: 176, 20.IV.1937, Mazatenango; T6 66: 225, 16.IX.1938, Villa Nueva; T1 69: 123, 21.V.1940, Sta. Ana Chimaltenango; T1 70: 184, 18.VI.1941, S. Sebastián, Antigua; T1 70: 224, 26.VII.1941, Mixco; Oficios: 287, 31.VII.1941, Patzicia; T1 70: 270, VII.1941, Sanarate; Oficios: 540, 2.X.1942, Barbarena; s.c. 4.XII.1942 y T1 66:

La Iglesia en la Encrucijada Hispania Sacra 49 (1997) 
ciones contra algunos Intendentes y Jefes Políticos de favorecer el desarrollo del protestantismo y perseguir a los católicos. b) La opinión, bastante generalizada, de que el mal comportamiento de algunos sacerdotes beneficiaba al proselitismo protestante; aunque, conocida la preocupación del Arzobispado por este problema, las cofradías pudieron, también, realizar acusaciones en este sentido, para favorecer sus intereses. c) En ocasiones, los castigos que impuso la Curia a algunas parroquias, por la desobediencia de los cofrades, favorecieron su desarrollo. d) La creencia, y esto es lo más importante para entender las implicaciones de este fenómeno en el comportamiento de la Iglesia guatemalteca, de que su desarrollo había sido posible fundamentaimente por la falta de clero y la debilidad de la Iglesia y que, por lo tanto, sería muy fácil vencerlo multiplicando el número de sacerdotes y la predicación. e) La idea de que afectaba sobre todo a los indígenas, los niños y la gente ignorante, lo que venía a reforzar la idea anterior.

$5^{\circ}$.- En muchas ocasiones los castigos impuestos por la Curia provocaron el alejamiento de los fieles más que la eliminación de su indisciplina ${ }^{52}$.

$6^{\circ}$.- Las graves dificultades económicas de la Iglesia ${ }^{53}$.

\section{La Década Revolucionaria}

Entre 1944 y 1954 los problemas de la Época anterior se vieron agravados por elementos nuevos y nuevos problemas:

$1^{\circ}$.- De la época anterior perduraron la falta de clero ${ }^{54}$, los conflictos con las cofradias en torno a la autoridad y a las costumbres (en el Archivo Arzobispal

190, 29-IV-1943, Suacite; T1 68: 391 25.VIII.1942 y T1 70: 484, 8.X.1942; T1 65: 131, 25.III.1944, Livingston; T1 65: 36, 4,XII.1944, S. Cristóbal, Jutiapa; T3 54: 1948, Encuesta sobre el protestantismo en la Arquidiócesis de Guatemala.

52 AHA Oficios: 375, 6.IX.1937, Mataquescuintla; T1 70: 206, 3.VII.1941, Sta. Ana Chimaltenango; T1 70: 224 y 287, 26.VII.1941, Patzicía.

53 AHA Oficios: 130, 29.IV.1939; T1 65: 278, 24.VIl.1944, S. Sebastián, Antigua.

54 AHA T1 64: 28.I.1945, Sta. Catalina Pinula; T1 64: 2.II.1945, Catedral, Antigua; T2 66: 75, 11,II.1945, Patzum; T1 63: 78, 21.II.1945, Livingston; T1 64: 288, VIII.1945, Escuintla; T3 53: 10.IX.1945, Comalapa; T1 64: 316, 21.IX.1945, Conguaco; T1 64: 328, DX.1945, Sta. María de Jesús; T1 64: 348, 17.X.1945, Antigua; T3 53: 20.XI.1945, Barbarena; T1 63: 95, s.f., Xenacoj; T1 63: 207 , 4.VI.1945, Villa Zaragoza, Chimaltenango; Oficios: 367, 1946, s.f., sobre las dificultades para mantener la asistencia religiosa en la Penitenciaría central; T2 63: 109, 25-IJ-1946, S. Andrés Jtzapa; Oficios: 49, 14.V.1946, Duefias; T1 63: 595, 4.XII.1946,Guazacapán; T1 63: 617, 10.XII.1946, Livingston; Oficios: 277, 24.VIII.1946, sobre la multiplicación de pueblos y actividades en manos de un mismo sacerdote; T2 66: 198, 11.V1.1947, y Oficios: 220, 18.VI.1947, finca 'E1 Estor'; T2 66: 347 , 12.DX.1947, Asuncion Mita; T2 66: 279, 14.IX.1947, Livingston; T2 68: 570, 30.XII.1947, Casillas; T3 53: 18.VIII.1947, Comalapa; T3 53: 24.X.1947, Coatepeque; T1 65: 33, 9 y 10.XIl.1948, Nuevo

La Iglesia en la Encrucijada Hispania Sacra 49 (1997) 
he podido localizar referencias a ochenta y un conflictos, y en la prensa se pueden encontrar noticias de otros muchos) ${ }^{55}$, el desarrollo del protestantismo,

Progreso; T2 70: 64, 18.Iil.1949, Puerto Barrios; T2 71: 177, s.f., Villacanales; T2 70: 130 y 134, 5 y 10.VI.1949, S, Lucas Sacatepéquez; T2 70: 109, 16.V.1949, Santiago Sacatepequez; Oficios: 354, 13.VI.1949, Sta. Lucia Sacatapéquez; T2 72: 439, 15.VIII.1949, Sto. Dorningo Xenacoj; T2 70: 184, 1.IX.1949, Cuyotenango; T2 70: 285, 294 y 307, 30.XI, 9.XII y 21.XIt.1949, Livingston; T2 70: 293, 3.XIl.1949, Tecpán; T2 70: 313, s.f., Santo Domingo Xenacoj; T2 71: 156 y 169, 17 y 22.III.1950, y Oficios: 151 y 157, 22 y 23.IIl.1950, Maxatenango; T2 72: 272, 15.V.1950, Amatitán; T2 72: 449, 27.VIII.1950, Zaragoza; Corresp. 1950: 27.VII.1952, S. Raymundo.

55 San Juan Comalapa (T1 64: 11.XII. 1944); Sta. Lucia Cotzumalguapa (T1 63: 7, 4.I.1945, y T1 64: 304, 10.IX.1945); Sta. Cruz de Milagro, Vieja Guatemala (T1 63: 4I, 25.I.1945); Jutiapa (T2 66: 71, 9.II.1945); S. Joaquin Villacanales (T1 63: 88, s.f.); Gualan (T1 63: 202, 31.IV.1945); Mataquescuintla (T1 64: 271, 5.VIII.1945); S. Luis Jilotepeque (T1 64: 332 y 335, 4 y 5.X.1945); Chiquimula (T2 64: 143, 8.III.1946); S. Agustín Acasaguastlán (Oficios: 13.IV.1946); El Calvario (T1 63: 525, 24.X.1946); S. Miguel Baquil (T1 63: 584, s.f.); Mazatenango (T2 66: 351, XI.1946); S. José Pinula (T1 63: 653, s.f.); Mazatenango (T3 53: 27.I.1947, T3 60: II.1947, Oficios: 29.III.1947, y T3 53: 2.IV.1947); S. Pedro Ayampuc (T2 66: 76, 11.II.1947); S. Pedro Sacatepéquez (Oficios: 81, 26.II.1947); Mataquescuintla (T2 66: 133, 31.JII.1947); Los Remedios, Antigua ('T2 65: 10.V, 24 y 25.V1 y 3.VII.1947, Oficios: 388 y 455, 24.IX y 14.XI.1947); Zacapa (T2 66: 200, 12.VI.1947); Santiago Mataquescuintla (T2 66: 229, 21.VII.1947); Mazatenango (T2 66: 388, 17.XII.1947, y Oficios: 484, 23.XII.1947); Palín (Oficios: 488, 30.XII.1947); Mazatenango (T3 59: 9.I.1948); S. Sebastián, Antigua (T2 67: 112, 272 y 289, 27.II, 16.II y 14.V.1948); Escuela de Cristo, Antigua (T2 67: 153, 24.III.1948, T2 68: 383, 16.VII.1948, y Oficios: 251, 17.VII.1948); S. Agustín Sumpango (T2 67: 290, 22.V.1948, y Oficios: 186, 2.VI.1948); Nuestra Señora de la Candelaria (T1 65: 22, 6.XI.1948); Alotenango (T2 68: 542, 19.XI.1948); Sta. Lucia, El Progreso (Oficios: 499, 29.XI.1948); Quetzaltepeque (T3 59: 4.XII.1948); María Auxiliadora, Guatemala (T3 59: 22.IV.1949, y T2 70: 91, 2.V.1949); Chimaltenango (T2 70: 108, 16.V.1949, y T3 59: 27.VI.1949); S. Juan Comalapa (T2 70: 150, 2.VII.1949); Chichicastenango (T2 70: 154, 10.VII.1949); S. José Baquil, Chimalienango (T2 70: 212 y 251, 28.IX y 30.X.1949, y T3 59: 5.XII.1949); S. Bartolome, Mazatenango (T2 70: 275, 17 y 30.XI.1949); Comalapa (T2 70: 281, 294 y 311, 24.XI, 4 y 26.XII.1949); S. Juan Bautista, Amatitlan (T3 59: 31.XII.1949; T2 71: 69, 4.1.1950, y T2 72: 192, 193, 196 y 343, 2, 3 y 9.IV y 20.VI.1950); Comalapa (T2 71: 84, 2.II.1950, y Oficios: $64,68,143$ y 163,1 y 6.11 y 16 y 26.III.1950); Sta. María del Naranjo (T2 71: 86, 4 y 6.II.1950, y T2 72: 420, V.1950); Sanarate (Oficios: 164, III.1950, y T3 60: 226, 22.IV.1950); Tecpan (T2 71: 184, 30.III.1950, y T2 72: 244, 245,277 A y 430,2 y 14.V y 3.VIII.1950); Guazacapán (T3 60: 202 y 283, 9.IV y 18.V.1950); S. Jorge la Laguna (s.c. dos cartas del 8 y 22.VIII.1950); S. José Baquil, Jilotepeque (T2 72: 481, 18.IX.1950); Asunción Mita (Oficios: 521, 10.XI.1950); Sacatepéquez (T2 71: 87, 6.11.1950); Pazaco (T2 72: 567, 14.XI.1950); Puerto Barrios (Oficios: 255A, 15.V.1950); Jumaytepeque (T3 60: 58 y 158, 19 y 21.I.1951); Sta. Rosa de Lima (T3 60: 322 y 357, 18.VI y S.VII.1951); Masagua, Escuintla (T3 60: 104 y 123, 11 y 26.II.1951, y Oficios: 72 y 72A, 24.Il y 1.III.1951); Puerto Barrios (Oficios: 72A, 23.II.1951); Villacanales (T3 60: 156, 18.IIl.1951); S. Pedro Sacatepéquez (T3 60: 157 , 19.III.1951); Sololá (T3 60: 170, 27.III.1951); Tecpán (T3 60: 296 y 331, 1 y 15.VI.1951, Oficios: 340, 2.VIII.1951); S. José, Antigua (T3 60: 306, 6.VI.1951); S. Antonio Retalhuleu (T3 60: 398, 30.VII.1951, y Oficios: 347, 6.VIII.1951); S. Pedro Sacatepéquez (T3 58: 595, 28.XI.1951, y Oficios: 528, 1.XII.1951); Sta. Catarina Barahona (T3 60: 249, 8.V.1951); Villa Canales (T3 58: 454, 28.VIII.1951); S. Juan Sacatepequez (Oficios: 398, 3.IX.1951, y T3 58: 461, 3.IX.1951); S. Martineco, Cuilapa (T3 58: 626, 12.XII.1951); Patzum (T3 58: 183, 156 y 172, 2.X y 8.XII.1952, y Oficios:

La lglesia en la Encrucijada Hispania Sacra 49 (1997) 
que era analizado del mismo modo que en años anteriores ${ }^{56}$ y los conflictos con las autoridades civiles locales ${ }^{57}$.

$2^{\circ}$.- Pese a estas pervivencias, sin duda alguna, en estos años, lo fundamental son los nuevos problemas políticos, estructurados en una doble dirección: la respuesta del pueblo a los esfuerzos de movilización política desarrollados por los revolucionarios y la respuesta - de carácter político- dada por el clero.

Los revolucionarios de 1944 creyeron en la necesidad de integrar a las masas, mayoritariamente indígenas, en la nación ${ }^{58}, \mathrm{y}$, ante la política que desarrollaron, las masas campesinas respondieron positivamente, canalizando a través de partidos y sindicatos sus problemas, incluidos los enfrentamientos con la autoridad eclesiástica ${ }^{59}$.

De este modo, en los conflictos entre el clero y las cofradías habrían de introducirse nuevos elementos. El pueblo empezó a apelar, cada vez con más frecuencia y agresividad, a la autoridad civil (procesos judiciales, protestas, conflictos laborales, etc.), a la opinión pública y a los partidos políticos y sindicatos; mientras las peticiones cada vez fueron más violentas, impertinentes $\mathrm{e}$ imperativas.

La Curia no disimuló su desagrado ante la intromisión de todos estos factores. Monseñor Rossell, en 1955, interpretó estos hechos como infiltración comunista y recordó la propaganda electoral realizada por grupos revolucionarios con el Corazón de Jesús ${ }^{60}$.

\footnotetext{
278 y 495, 7.VIII y 8.XII.1952); Nuestra Señora de los Remedios, Antigua (T3 57: 21, 21.I.1952); Chimaltenango (Corresp. 1950: 1.III y 17.III.1952, T3 57: 47 y 56, 4 y 12.IIl.1952); Comalapa (T3 57: 73, 23.IV.1952); Sta. María Cauque (s.c. 12.IX.1952); S. Martín Jilotepeque (T3 54: 93, I.VI.1952); Aldea Cerrito (T3 58: 175, 15.XII.1952); Villa Nueva (T3 54: 51, 27.JV.1953, y Oficios: 161, 8.V.1953); en un lugar no especificado (Oficios: 183, 20.V.1953); Palín (Corresp. 1950: 18.V1.1953, T3 54: 109 y 115, 18 y 27.VI.1953, y Oficios: 245, 30.Vl.1953); Quiché (T3 54: 145, 19.VIII.1953); Sta. Catarina Pinula (T3 56:, 2 y 28.XIl.1954); La Merced, Antigua (T3 56: 21. III y 7.IV.1954); S. José Pinula (s.c. y s.f.); S. José Palencia (Oficios: 100, 11.II. 1954).

56 AHA T1 64: 274, 13.VIII.1945, Comalapa; T1 63: 584, s.f., S. Miguel Baquil; T1 65: 30, 4.XII.1948, y T2 70: 11, 17.I.1949, S. Cristóbal, Jutiapa; T2 71: 184, 30.III.1950, y T2 70: 244, 245, 277A y 430, 2 y 14.V y 3.VIII.1950, Tecpán; T2 71: 87, 6.II.1950, Santiago Sacatepéquez; Cortesp. 1950: 1 y 17.III.1952, T3 57; 47 y 56, 4 y 12.III.1952, Chimaltenango; T3 54: 183, 10.VIIl.1953;

57 AHA T1 64: 240, 6.VII.1945, Concepcion Sanayac; T2 70: 123, 25.V.1949; Retalhuleu.

${ }^{58} \mathrm{La}$ legislación no dejó de reflejar este interes y, por ejemplo, la camparia de alfabetizacion trato de fomentar el patriotismo y el espiritu revolucionario, ante la preocupación de la Iglesia.

${ }^{59}$ Probablemente el gran éxito de los partidos políticos y los sindicatos fue posible gracias al golpe que habia representado la política de intendentes de Ubico en el debilitamiento de la autoridad de los principales.

${ }^{60}$ Mons. Rossell, "Tácticas y obras del comunismo en Guatemala", intervención en el $M /$ Congreso Católico de Vida Rural, Panamá, ECA XI:108(sept. 1956)455-65.
} 
Es muy significativo el informe que los jesuitas de La Merced prepararon sobre el conflicto en el que se vieron envueltos en la Semana Santa de 1954, con los cargadores de su iglesia. Este conflicto fue llevado a la prensa por los cargadores y, en todo momento, la reacción de los jesuitas estuvo coartada por el miedo a que el agravamiento de la situación favoreciera a los comunistas o diera al gobiemo un pretexto para expulsarlos ${ }^{61}$. No es en ningún modo impensable que el resto de la Iglesia sintiese temores parecidos y, de todos modos, es indiscutible que si experimentaron un grave malestar ante la creciente indisciplina que, la politización generada por la Revolución provocó en las cofradías, hermandades y demás asociaciones religiosas.

De este modo, cuando los conflictos locales fueron agravados por la política nacional, la conversión al comunismo de los costumbristas vino a preocupar a la Iglesia y a justificar su idea de que el liberalismo había descristianizado a la sociedad, haciéndola propensa al comunismo.

Íntimamente relacionado con todo lo anterior, surgió un tema nuevo de gran importancia: la politización del clero, que se fue radicalizando y generalizando, caracterizada por varios hechos: la Curia en un principio aconsejó a su clero que no participara en política, pero luego dejo de hacerlo, $\mathrm{y}$, al tiempo, ante el Gobierno, el Arzobispado siempre negó este fenómeno. Los partidos y sindicatos revolucionarios intentaron, por su parte, controlar las cofradías y demás asociaciones religiosas, introduciendo también de este modo la política en los conflictos ya tradicionales. Desde el primer momento el problema se plantea en torno a una interpretación distinta de lo que es y lo que no es política y sobre si puede considerarse que los sacerdotes católicos se inmiscuyen en política al atacar al comunismo.

En esta situación, la actuación de los partidos políticos indica la inmensa importancia del factor religioso en la vida y en el control de las comunidades, y las relaciones con el Gobierno, desde el comienzo malas, se fueron agravando progresivamente.

Cuando, en vísperas de la Revolución el Gobiemo del General Ponce acusó a varios sacerdotes de actividades políticas, la Curia Arzobispal, tras hacer las averiguaciones pertinentes, recomendó al clero, nacional y extranjero, abstenerse de tales actividades ${ }^{62}$. Durante mucho tiempo se comportaría del mismo modo: en febrero de 1945, ordenó impedir que se repartieran en las iglesias oraciones sin el visto bueno de la autoridad, para evitar las cadenas y las oraciones de tipo político ${ }^{63}$; en agosto de 1946 , por medio de una Circular el Ar-

61 ASJ-CA: 8.4 GUATEMALA: Guatemala La Merced, caso de los cargadores 1954.

62 AHA Oficios: 409CA, 18.X.1944, y T1 65: s.f.

63 AHA T1 64: 75, 16,II.1945.

La Iglesia en la Encrucijada

Hispania Sacra 49 (1997) 
zobispo de Guatemala ordenó a los sacerdotes de la Arquidiócesis no intervenir en las luchas políticas y ser prudentes en sus declaraciones, para que no pudieran ser interpretadas en sentido político ${ }^{64}$; en cartas posteriores el Arzobispado repetiría las mismas recomendaciones y recordaría a los laicos el apoliticismo de la Iglesia ${ }^{65}$; prohibi6 las celebraciones religiosas de tipo político, incluso las misas por los caídos ${ }^{66}$; se preocupó por el comportamiento político de algunos sacerdotes ${ }^{67}$; etc.

Pese a todo fueron muchos las sacerdotes que, de un modo u otro, no siguieron estas indicaciones, llegando incluso, como el párroco de Chimaltenango, a entablar polémicas abiertas con los líderes políticos ${ }^{68}$; 0 , sólo otro ejemplo, como el párroco de Tejutla, a utilizar los sermones dominicales para hablar en contra del Gobiemo y del Partido de Acción Revolucionaria ${ }^{69}$.

El Arzobispado quería mantener a sus sacerdotes alejados de los conflictos políticos, probablemente por temor a las represalias y complicaciones y por una cierta inercia originada en las actitudes de épocas pasadas; pero, esto no quiere decir que sus relaciones con el Gobierno de la República fuesen buenas, ni que renunciara a participar en los debates políticos de ámbito nacional, como prueba la correspondencia cruzada entre el Ministerio de Gobernación y la Curia Arzobispal en 1946. El Ministro de Gobernación se quejó el 23 de febrero a Monseñor Rossell de que varios religiosos estaban haciendo política, con el pretexto de combatir «lo que se ha dado en llamar comunismo, doctrina que en Guatemala nunca ha existido y que el Gobiemo es el primero que se empeña en combatir». El 6 de marzo respondió el Arzobispo: apoyándose en las mismas medidas tomadas por el Gobierno (la clausura de la Escuela Claridad y de un sindicato campesino), afirmó que en Guatemala si había comunismo, y no aceptó que fuera ocupación exclusiva del Gobierno luchar contra él, sino, al contrario, obligación de cualquier ciudadano; afirmó también que había prevenido al clero de que no debía participar en política, pero se negó a hacer tal indicación a los laicos, por ser contraria al Derecho Natural y a la Constitución ${ }^{70}$.

En agosto se volvió a repetir un intercambio de cartas semejantes, en las que el Gobiemo acusaba al clero falangista de agitar a la masa ignorante en beneficio de la reacción, y la Curia solicitaba que concretase sus acusaciones

64 AHA Oficios: 21.Vill.1946.

65 AHA Oficios: 23 y 24.VIII.1946.

66 AHA T1 63: 498, 9.X.1946, y T3 53, 6, 7 y 18.X.1946.

67 AHA T1 63: 585, XI.1946.

68 AHA T3 60: XI.1946, "Respuesta del parroco de Chimaltenango a los paristas", editada como hoja suelta y publicada por El Libertador el 10 de octubre.

69 AHA T3 53: 24.IV.1947, y Oficios: 1.V.1947, 28.

${ }^{70}$ AHA T3 53: 23.II.1946; Oficios: 24(M), 6.III.1946. 
para poder corregir a sacerdotes en concreto ${ }^{71}$. Por último, en octubre, un nuevo intercambio de correspondencia permitió al Arzobispado reafirmar sus posiciones y protestar contra una serie de atropellos de los que se creía objeto ${ }^{72}$.

Corresponde a junio de 1945 la primera referencia que he encontrado de un sacerdote que utilice el apelativo comunista para referirse a un grupo de cofrades indisciplinados ${ }^{73}$. Los cuales, también por primera vez, envían noticia de sus conflictos con el sacerdote a un diario: El Libertador. Era la primera vez, pero el proceso no había hecho más que comenzar. La utilización de la religión con finalidades políticas no fue una actitud exclusiva de ningún sector político concreto: los arevalistas, ante la manifestación de septiembre de 1946, afirmaron en su propaganda que el Arzobispo apoyaba la manifestación en favor del Gobierno ${ }^{74}$, por otra parte, Ia filial del Frente Popular Libertador en Cobán utilizó la estampa del Sagrado Corazón como elemento de propaganda electoral, obligando al Arzobispo a desautorizarlo por escrito ${ }^{75}$.

Como ya he señalado, a lo largo de toda la Década Revolucionaria los feligreses recurrieron en numerosas ocasiones a instancias civiles para buscar soluciones a sus conflictos con los sacerdotes; sólo unos ejemplos: un grupo de feligreses de Santa Catarina Mita denunci6 al P. Schumacher por ladrón, por haber trasladado de una Iglesia a otra dos copones ${ }^{76}$; los cofrades de los Remedios, Antigua, enviaron una carta a El Imparcial, protestando contra su párroco ${ }^{77}$; si habían sido frecuentes las solicitudes de sacerdotes por parte de los pueblos al Arzobispo, en 1947 por primera vez lo harán a través de instituciones políticas: el Secretario General del Frente Popular Libertador y un alcalde municipal ${ }^{78}$; mientras los cofrades de muchas comunidades se afiliaban a los partidos oficialistas ${ }^{79}$, estos partidos y la prensa revolucionaria seguían haciendo públicos los conflictos y la feligresía protestaba por medio de la

7 Nota del Ministerio de Gobemación y Justicia No 7429 del 9.VIII.1946 y AHA Ofícios: 20.VIII.1946, 65. Acción Social Cristiana: 17.X.1946 y El Libertador. 10.X.1946: conflictos del P. Tello, de Chimaltenango, con los paristas, llevado por ambas partes a la prensa; Verbum: 22.XI.1946.

72 AHA Oficios: $338,23 . X .1946$.

73 AHA T2 68: 509, 7.X.1946.

74 AHA T1 63: 453, 2.IX.1946.

75 AHA s.c.: carta de Baltasar Morales del 27.X.1948 y Oficios: 487, 2.XI.1948.

76 AHA T3 53: 4.V.1947, Oficios: 200, 29.V.1947, y T2 66: 237, 4.VIll.1947. Tras un informe enviado, al Ministerio de Gobemación y Justicia, por el Arzobispado, sobre los derechos de los párro$\cos$ con respecto a los bienes sagrados y parroquiales, no lleg6 a procesarse al sacerdote, pero el conflicto indica las nuevas formas de actuación de las cofradias.

$n$ AHA T2 65: 10.V.1947.

78 El Secretario General del Frente Popular Libertador, Ricardo Asturias Valenzuela, escribió a Rossell porque los indigenas de Comalapa le habian pedido su ayuda para conseguir un sacerdote, preferiblemente el P. Gil, AHA T3 53: 18.VIII.1947; AHA T3 53: 24.X.1947, Villa Coatepeque.

79 AHA T3 59: 4.XII.1948, Quetzaltepeque. 
prensa ${ }^{80}$; no en pocas ocasiones intervenían los Gobernadores civiles a favor de las cofradías opuestas al clero ${ }^{81}$; en San Lucas Sacatepéquez el sacerdote hizo uso del púlpito para atacar a los partidarios del alcalde ${ }^{82}$; en Amatitlán ante los problemas entre el sacerdote y la Acción Parroquial, ésta amenazo con llevar los conflictos a la prensa y buscar por su cuenta un sacerdote si el Arzobispado no respondía a sus exigencias ${ }^{83}$; etc.

La revista $E C A$, comentando este tipo de conflictos, recogió claramente los sentimientos de la Iglesia: «El parismo metió la zarpa en las solemnidades de la Semana Mayor». En términos semejantes se expresaba Acción Social Cristiana ${ }^{84}$. El malestar era explicable: al tiempo que los partidos políticos se introducían en las comunidades, los conflictos se multiplicaban y alcanzaban un grado de violencia hasta entonces desconocido; no en pocos sitios había llegado a peligrar la integridad fisica de los sacerdotes, por ejemplo, en San Agustín Acasaguastlán o Santa María del Naranjo.

Por estas fechas, ya clausurada Radio Pax, las relaciones entre el Gobierno y el Arzobispado se habían roto totalmente, como prueba la carta enviada por este último a raíz de un robo sacrílego, donde afirma no confiar ya en la justicia humana ${ }^{85}$.

En Nueva Santa Rosa el sacerdote acusó al secretario del Partido de Acción Revolucionaria de Jumaytepeque de ser el instigador de los conflictos ${ }^{86}$; la Hermandad de Puerto Barrios hizo pública una carta contra el parroco ${ }^{87}$; en tono amenazante se dirigieron los cofrades de San Pedro Sacatepéquez al Arzobispo ${ }^{88}$; en otro conflicto los cofrades de Tecpán, algunos de los cuales estaban afiliados al Partido de Acción Revolucionaria, volvieron a recurrir a la autoridad civil, como también lo hicieron los de Comalapa, provocando en ambos casos el malestar de la Curia y la suspensión de la asistencia religiosa ${ }^{89}$;

${ }^{80}$ El Libertador. 10.VII y 18.IX.1948, Sta. Ana Chimaltenango y Tejutla.

81 AHA T3 57: 21, 21.I.1952, los Remedios, Antigua; Corresp. 1950: 1 y 17.II.1952, T3 57: 47 y 56, 4.II.1952, 12.III.1952, Chimaltenango; s.c. 12.IX.52, Sta. María Cauque; T3 60: 322 y 357 , 18.V1 y 5.VII.1951, Sta Rosa de Lima; T3 60: 104 y 123, 11 y 26.II.1951, y Oficios: 87, 24.II y 1.IIl.1951, Masagua, Escuintla; \$.c., 8 y 22.VIll.1950, S. Jorge la Laguna; T2 70: 212 y 251, $28 . I X$ y 30.X.1949, y T3 59: 5.XIl.1949, S. José Baquil; T2 71: 84, 2.II.1950, y Oficios: 64, 143 y 163, 1 y 6.II y 16 y 26.III.1950, s.c. carta de 3.IV.1950, Comalapa.

82 AHA T3 59: 28.XII.1949.

83 AHA T2 71: 69, 4.J.1950, y T2 72: 192 193, 196 Y 343, 2, 3 y 9.IV y 20.VI.1950.

84 ECA V:40(may 1950)62; Acción Social Cristiana 13.IV.1950, p. 5.

85 AHA Oficios: 174, 1.IV.1950.

86 AHA T3 60: 58 y 158, 19 y 21.I.1951.

87 AHA Oficios: 72A, 23.II.1951.

88 AHA T3 60: 157, 19.II1.1951.

89 AHA T3 60: 296 y 331, 1 y 15.VI.1951, y Oficios: 340, 2. VIII.1951, Acción Social Cristiana: 14.VI.1951, p. 11. 
en San José, Antigua, uno de los dos grupos que se enfrentaban por el control de la Iglesia argumentó tener derecho por pertenecer al partido oficialip; Adolfo Ortíz, maestro de capilla de San Pedro Sacatepéquez, llevó sus problemas con el párroco ante el Tribunal de Trabajo, provocando el enfado del Arzobispado ${ }^{91}$; el alcalde de San Juan Sacatepéquez se quejó al Arzobispo de que, una vez concluidas las elecciones, la planilla reaccionaria se había reunido, con armas, en el convento parroquial ${ }^{92}$.

En 1952, al tiempo que, con insistencia, seguía el Gobierno protestando de la actitud políticamente hostil adoptada por el clero ${ }^{93}$, la Curia Arzobispal ya no hacía ningún intento por evitar estas actitudes, aunque continuó negándolas, al tiempo que afirmaba su derecho a oponerse al comunismo, y su respeto por el Gobiemo, de cuya legitimidad decía no dudar ${ }^{94}$.

En 1953 desaparecieron las protestas formales del Gobierno - - , por lo menos, no he encontrado ninguna en el Archivo Arzobispal-, pero no el fuerte enfrentamiento político. Los conflictos eran cada vez más violentos y la preocupación ante ellos mayor; en el Quichê se llegó a amenazar al Arzobispo ${ }^{95}$.

La Curia, pese a afirmar lo contrario, estaba ya enfrentada abiertamente con el Gobierno: autorizó varias oraciones contar el comunismo\%; solicitó al periódico la Pulga que publicase una aclaración del P. Herrera ${ }^{97}$, demostraba, así, el gran cambio que había experimentado desde los primeros años de la Revolución, cuando recomendaba prudencia a su clero, y su nueva actitud; el P. Méndez se dirigió a la prensa para defenderse de las acusaciones que contra él habían hecho las autoridades de San José Pinula98; etc.

$3^{\circ}$.- Ligados a la tensa situación política se observan otros problemas que vinieron a complicar la situación: se multiplicaron los castigo impuestos por la Curia ${ }^{99}$; las asociaciones de acción católica provocaron divisiones en los pue-

90 AHA T3 60: 306, 6.VI.1951.

91 AHA T3 58: 595, 28.XI.1951, y Oficios: 528, 1.XII.1951.

92 AHA T3 58: 602, 2.XII.1951.

93 AHA T3 57: 39, 5.11I.1952; T3 58: 167, 7.XI.1952, Jutiapa; T3 58: 170, 20.XI.1952, Cobán; s.c., carta del 18.XII.1952, S. Andrés Sajcabaja; Diario de Centro América: 6, 10 y 13.VI.1952, I: 13.VI.1952, Finca Mauricio; AHA s.c., cartas de 31.V y 11.VI.1954, Finca el Zapote, Escuintla; AHA T3 58: 110, 2.VI.1952, Patulul, Chiquimula.

94 AHA s.c., carta del 17.VI.1952, al Ministerio de Gobernación; AHA s.c., carta al Ministro de Gobernación del 31.V.1954.

95 AHA T3 54: 145, 19.VIII.1953.

96 AHA T3 56: 9.IV.1954; T3 54: 144, 19.VIII.1953.

97 AHA Oficios: $325,3 . I X .1953$.

98 AHA Corresp. 1950: carta del 21.XII.1953.

99 AHA T1 63: 203, 5.VI.1945, Comalapa.; Oticios: 29.XI.1948, 499, Sta. Lucia, El Progreso; T2 71: 184, 30.III.1950, y T2 72: 244, 245, 277A y 430, 2 y 14.V y 3.VIII.1950, Tecpán; 
blos, al enfrentarse a las cofradías tradicionales, y conflictos, todavía incipientes, entre religiosos; por otra parte, estas asociaciones no siempre se mantuvieron fieles y obedientes al clero que las había fundado ${ }^{100}$; aparecieron las primeras acusaciones contra el clero extranjero ${ }^{101}$, si bien no hay pruebas concluyentes đe que éste provocara más conflictos que el nacional.

\section{CONCLUSIONES}

Creo posible afirmar que cualquier intento por comprender el proceso en el que se ve inmersa la Iglesia católica en Guatemala durante la Década Revolucionaria pasa por la consideración de tres cuestiones: una herencia de debilidad consecuencia de la política religiosa de los liberales que incapacitó durante años a la Iglesia para cumplir muchos de sưs más elementales compromisos; el establecimiento de una Constitución con rasgos importantes de anticlericalismo que no hace otra cosa que reflejar los planteamientos doctrinales de los sectores revolucionarios, y la movilización política que agita a toda la República y genera, no sólo en la Iglesia, inseguridad y miedo ${ }^{102}$.

100 AHA T2 70: 212 y 251, 28.IX y 30.X.1949, y T3 59: 5.XI1.1949; T2 71: 69, 4.I.1950, y T2 72: 192, 193, 196 y 343, 2,3 y 9.IV y 20.VI.1950, Amatitlán; T2 71: 84, 2.II.1950, y Oficios: 64, 68, 143 y 163,1 y 6.II y 16 y 26.11 .1950, existe también una carta sin clasificar del 3.IV.1950, Comalapa; T2 72: 481, 18.IX.1950, S. José Baquil; T3 60: 58 y 158, 19 y 21.I.1951, Nueva Sta. Rosa; T3 58: 183,156 y 172, 2.X y 8.XII.1952, y Oficios: 278, y 495, 7.VIII y 8.XII.1952, Patzum; T3 54: 145, 19.VIII.1953, Quiché.

101 AHA dos cartas sin clasificar del 8 y 22.VIll.1950, S. Jorge La Laguna.

102 Más allá de la Iglesia católica, sobre el miedo y sus repercusiones en amplios sectores de la sociedad guatemalteca ha hablado Jim Handy, Revolution ..., ob. cit., pp. 52 y ss.; y sobre esta cuestión es necesario tener presente el recuerdo, permanente durante toda la Década Revolucionaria, de Patzicía. 